\title{
Modulatory Effect of Phytoestrogens and Curcumin on Induction of Annexin 1 in Human Peripheral Blood Mononuclear Cells and their Inhibitory Effect on Secretory Phospholipase $\mathrm{A}_{2}$
}

\author{
Waqas Ahmad, Endang Kumolosasi*, Ibrahim Jantan, Malina Jasamai and Emil \\ Salim \\ Drug and Herbal Research Center, Faculty of Pharmacy, Universiti Kebangsaan Malaysia, Jalan Raja Muda Abdul Aziz, 50300, \\ Kuala Lumpur, Malaysia.
}

*For correspondence: Email: e_kumolosasi@yahoo.co.id; Tel: +60149208054

Revised accepted: 26 December 2013

\begin{abstract}
Purpose: To investigate the modulatory effects of phytoestrogens (coumestrol, daidzein and genistein) and curcumin on the induction and secretion of annexin-1 (ANXA-1) in human peripheral blood mononuclear cells (PBMCs) under inflammatory and non-inflammatory conditions, as well as their effect on the activity of phospholipase $A_{2}-V\left(s P L A_{2}-V\right)$.

Methods: The modulatory effects of phytoestrogens and curcumin on the induction ofANXA1 were investigated via sandwich ELISA method, while their effects on the activity of $S P L A_{2}-V$ were determined by photometric assays. Besides, the cell viability of these compounds was determined by standard trypan blue exclusion method using PBMCs.

Results: The results indicate a significant increase $(p<0.05)$ in the total content ofANXA1, particularly by coumestrol $(p<0.01)$, in both inflammatory and non-inflammatory cells. Besides, the compounds also exhibited a dose-dependent inhibition of $s P L A_{2}-V$ activity; however, among these compounds, curcumin and genistein were the strongest inhibitors with an $I C_{50}$ value of $11.1 \pm 0.3 \mu M$ and13.6 \pm 0.6 $\mu M$ respectively.

Conclusion: The investigated compounds have a potential to induce synthesis and secretion ofANXA1 as well as inhibitory activity of $s P L A_{2}-V$, suggesting their inhibitory role in phospholipid metabolism and inflammation.
\end{abstract}

Keywords: Inflammation, Annexin-1, Phospholipase $A_{2}$, Phytoestrogens, Curcumin.

Tropical Journal of Pharmaceutical Research is indexed by Science Citation Index (SciSearch), Scopus, International Pharmaceutical Abstract, Chemical Abstracts, Embase, Index Copernicus, EBSCO, African Index Medicus, JournalSeek, Journal Citation Reports/Science Edition, Directory of Open Access Journals (DOAJ), African Journal Online, Bioline International, Open-J-Gate and Pharmacy Abstracts

\section{INTRODUCTION}

Inflammation, a widely addressed issue with clinical implications, has attracted a lot of researchers in multiple disciplines. Mechanistically, inflammation is a complex set of interactions among soluble and cellular components, recruited at and by destruction of connective tissue. The major soluble components include certain intercellular messengers such as cytokines [1]. Among cellular components, blood-borne monocytes/ macrophages are an integral part of inflammation.

Among all the anti inflammatory mediators, Annexin 1 (ANXA 1) has been proven to be the key anti-inflammatory mediator to control the inflammatory cascades.ANXA1 is a $37-k d$ protein 
made up of 346 amino acids and the first member of the annexin super family of calcium and phospholipid binding proteins [2].ANXA1 and its $\mathrm{N}$-terminal portion can influence many inflammatory mechanisms and regulate the synthesis of eicosanoids, leukocyte migration and apoptosis of inflammatory cells [3]. The ability ofANXA1 to regulate the synthesis of inflammatory mediators (such as eicosanoids) is due to its ability to restrain the activity of phospholipase $A_{2}\left(P L A_{2}\right)$. PLA 2 is the only super family of esterases that slices the acyl ester linkage at the sn-2 site of membrane phospholipids, liberating free fatty acids and lysophospholipids [4]. These hydrolases are proinflammatory cytokines responsible for the release of arachidonic acid and eicosanoids synthesis. $\mathrm{PLA}_{2}$ can be segregated into three major classes, $\mathrm{Ca}^{+2}$ dependent cytosolic $\mathrm{PLA}_{2}$ $(\mathrm{cPLA}), \mathrm{Ca}^{+2}$ independent cytosolic PLA $\left.\mathrm{PLLA}_{2}\right)$ and secretory $\mathrm{PLA}_{2}\left(\mathrm{sPLA}_{2}\right)$. Amongst these, $\mathrm{sPLA}_{2} \mathrm{~S}$ are the main contributors for the extensive production of arachidonic acid in inflammatory pathways [5].

To counteract the mediators of inflammatory cascades, a number of anti-inflammatory agents have been used. Among these, glucocorticoids (GCs) are the mainstay for the management of various inflammatory and immune disorders. GCs inhibit inflammation through a series of mechanisms, of which the induction ofANXA1 is a key mechanism. However, adverse effects associated with their long-term usage and development of resistance limit the use of GCs in chronic maintenance therapies. Among these deleterious effects, adrenal atrophy, cushing syndrome, hypertension, gastrointestinal bleeding, hypo-gonadism and fetal growth retardation [6] are associated with the long-term use of GCs. Considering the above mentioned clinical complications, global focus is to discover safer and more efficacious agents.

Curcumin, a natural compound found in curcuma species has been used successfully as an antiinflammatory agent. The pharmacological perspective of curcumin is under investigation and includes demonstration of its targets such as transcription factors, cytokines, cell adhesion molecules, surface receptors, growth factors and various kinases [7] thereby, causing either direct cellular pathway inhibition or activation of secondary cellular responses.

Furthermore, coumestrol, genistein and daidzein sourced from soybeans are the phytoestrogens. Phytoestrogens are substances that promote estrogenic actions in mammals and structurally resemble mammalian estrogen $17 \beta$-estradiol [8].
They mimic the biological activity of estrogens and have wide range of biological activities including estrogenic, antioxidant, anti inflammatory, antithrombotic, anti allergic, hypolipidemic and anti cancer properties [9].

Many biological and anti inflammatory effects of curcumin and phytoestrogens have been reported. However, to the best of our knowledge, their ability to modulate the induction ofANXA1 has not been reported to date. Therefore, the aim of the current study was to investigate the effect of phytoestrogens and curcumin on the induction ofANXA1 in human peripheral blood mononuclear cells as well as their inhibitory effects on the secretory phospholipase $A_{2}-V\left(s P L A_{2}-V\right)$ enzyme.

\section{EXPERIMENTAL}

\section{Materials}

Curcumin, coumestrol, daidzein and genistein were obtained from Sigma, Steinheim Germany. Compounds were dissolved in $5 \%$ dimethyl sulfoxide (DMSO) (Sigma, Steinheim, Germany) and diluted with PBS (phosphate-buffered saline) to obtain stock solutions of $1 \mathrm{mg} / \mathrm{mL}$. For the concentrations used in assay, calculated amount of stock solution were taken and diluted with complete medium. Complete medium consisted of RPMI-1640 supplemented with L-glutamin (Sigma, Steinheim, Germany), $10 \%$ heatinactivated newborn calf serum (Sigma, Steinheim, Germany), 10 mM HEPES (Sigma, Steinheim, Germany), and $100 \mathrm{U} / \mathrm{ml}$ penicillin and $100 \mu \mathrm{g} / \mathrm{ml}$ streptomycin (PAA, Pasching, Austria). The final concentration of DMSO in the solution applied to the PBMC was $<0.01 \%$.

\section{Separation of human peripheral blood mononuclear cells (PBMCs)}

PBMCs were obtained from blood donated by healthy volunteers. This study was approved by the human ethical committee of Universiti Kebangsaan Malaysia (UKM) (approval no. UKM 1.5.3.5/244/NF-050-2012) and conformed to the principles outlined in the Declaration of Helsinki [23]. Venous blood was collected in heparinized tubes and processed right away. Human PBMCs were isolated using gradient centrifugation in Lympoprep (Axis-Shield PoC AS, Oslo, Norway). Blood was diluted at 1:2 with RPMI-1640 medium, carefully layered on Lymphoprep, and centrifuged at $600 \mathrm{~g}$ for $20 \mathrm{~min}$ at $20{ }^{\circ} \mathrm{C}$. The PBMCs layer was removed and washed twice with RPMI-1640 and re-suspended in RPMI-1640 complete medium in a culture tube. The cells were adjusted to $5 \times 10^{5}$ cells $/ \mathrm{ml}$ by using haemocytometer. 


\section{Cell viability}

Cell viability was determined by the standard trypan blue exclusion method. The PBMCs $(5 \mathrm{x}$ $10^{5}$ cells $/ \mathrm{ml}$ ) were incubated with various concentrations of the compounds ranging from 5 to $100 \mu \mathrm{g} / \mathrm{ml}$, each in triplicate at room temperature for overnight. The blue dye uptake was a signal of cell death. The percentage viability was calculated from the total cell counts. The concentration of compounds at which viability was $>95 \%$ was used for further studies [10].

\section{Incubation of compounds in inflammatory and non-inflammatory PBMCs}

PBMCs were incubated overnight at $37^{\circ} \mathrm{C}$ and 5 $\% \mathrm{CO}_{2}$ either in the presence or in the absence of the test compounds. PBMCs were stimulated by $1 \mu \mathrm{g} / \mathrm{mL}$ of lipopolysaccharide (LPS) from Salmonella enteritica (Sigma, Steinheim, Germany) for the inflammatory condition. Dexamethasone at $0.4 \mu \mathrm{g} / \mathrm{mL}\left(10^{-6} \mathrm{M}\right)$ was used as a positive control and a mixture containing DMSO, PBS and RPMI-1640 was used as a negative control. Control groups were taken for stimulated as well as for non-stimulated PBMCs [11].

\section{Extraction of extracellular, intracellular and cell surface-associated Annexin 1}

Following incubation period, cells were gently centrifuged $(300 \mathrm{~g})$ for $5 \mathrm{~min}$ at $4{ }^{\circ} \mathrm{C}$ and the supernatant was separated for extracellular ANXA1. This centrifugation did not cause any lysis. The membrane bound ANXA1 was removed into the medium by washing the cells with $\mathrm{Ca}^{+2}$ free salt solution containing EDTA (Sigma, Steinheim, Germany). The pelleted cells were re-suspended in PBS containing $2 \mathrm{mM}$ EDTA and were further incubated for 2-3 min to get rid of ANXA1 attached to cell membranes. After incubation, cells were centrifuged again at the specifications mentioned before. The supernatant was isolated for measurement of membrane bound ANXA1. Subsequent to the removal of membrane associated ANXA1, cells were lysed and the lysate was taken for the calculation of entire intracellular ANXA1 [10].

\section{Quantification of Annexin 1 by ELISA}

ANXA1 was deliberated by sandwich Enzyme linked-immunosorbent Assay (ELISA) (USCN Life Science, China). The whole assay was performed as described by the manufacturer. ELISA was performed in duplicate, and data was obtained from three different donors.
Inhibition of secretory Phospholipase $A_{2}-V$ (sPLA ${ }_{2}$-V) Assay

Human recombinant $\mathrm{sPLA}_{2}-\mathrm{V}$ (Cayman) was employed as enzyme source. The activity of $\mathrm{sPLA}_{2}$ enzyme was calculated by a photometric assay based on the Ellman method [12]. Briefly, hydrolysis of sn-2 ester bond of the substrate 1,2-bis(heptanoylthio)-glycerophosphocholine by $\mathrm{PLA}_{2}-\mathrm{V}$ was followed by the exposure of free thiols. These thiols triggered the alteration of DTNB (5,5-dithio-bis-(2-nitrobenzoic acid) to 2nitro-5-thiobenzoic acid which was detected photometrically at $405 \mathrm{~nm}$. Afterwards, the assay was progressed in an aqueous buffer solution (pH 7.5) containing $\mathrm{KCl}(94 \mathrm{mM}), \mathrm{CaCl}_{2}(9 \mathrm{mM})$, Tris $(24 \mathrm{mM})$ and Triton-X $100(280 \mu \mathrm{M})$. Prior to the assay, substrate and $\mathrm{PLA}_{2}-\mathrm{V}$ were resuspended in assay buffer, and DTNB was dissolved in an aqueous solution of Tris- $\mathrm{HCl}(\mathrm{pH}$ 8). Enzyme and DTNB yielded final concentrations of $100 \mathrm{ng} / \mathrm{mL}$ and $87 \mu \mathrm{M}$ respectively. Assays were performed in 96-well microliter plates at room temperature containing DTNB, substrate solution and the respective test substance. $100 \%$ activity of enzyme was calculated by adding substrate and enzyme only. DMSO served as a negative control and was inactive at the concentration used in the assay $(1.7 \% \mathrm{v} / \mathrm{v})$.

\section{Statistical analysis}

The results are expressed as mean \pm standard deviation. All statistical analyses were performed using Graph Pad Prism 5. One-way ANOVA, followed by a post-test (Tukey's multiple comparison) was carried out when major divergence at $p<0.05$ and $p<0.01$ was present.

\section{RESULTS}

\section{Cell viability}

The cell viability was assessed prior to every experiment. The viability of PBMCs incubated in the presence of test compounds at concentrations $10 \mu \mathrm{g} / \mathrm{mL}$ was always greater than $95 \%$. The concentrations of compounds higher than $10 \mu \mathrm{g} / \mathrm{mL}$ decreased the cell viability below $95 \%$.

Effect on annexin-1 level and secretion in normal PBMC

The modulation of ANXA1 from PBMCs was observed by incubating the PBMC either in the presence or in the absence of curcumin, coumestrol, ginestein and diadzine at $10 \mu \mathrm{g} / \mathrm{mL}$ for all compounds. After incubation, intracellular, 

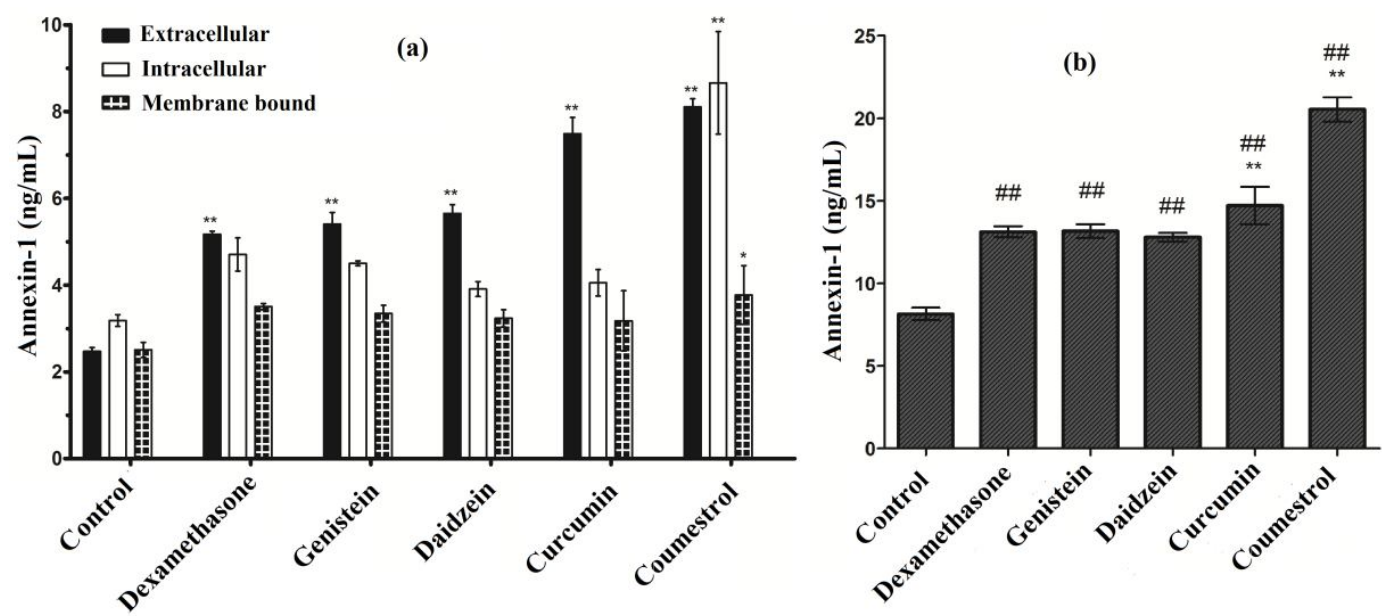

Figure 1: (a) Concentration of extracellular, intracellular and plasma membrane bound levels of ANXA1 in PBMC in the absence of compounds (control), Dexamethasone $(0.4 \mu \mathrm{g} / \mathrm{mL})$ and in the presences of compounds (10 $\mu \mathrm{g} / \mathrm{mL})$. (b) Total content of ANXA1 level in PBMC.

extracellular and membrane bound ANXA1 levels were calculated as described in methods. Considerable increase was observed in the basal levels of intracellular ANXA1 with all compounds; however, coumestrol exhibited maximum increase in the intracellular level of ANXA1. A significant increase in the level of extracellular ANXA1 was found for all the compounds as compared to control (Figure 1a). Results presented in Figure 1a illustrate an increase in plasma membrane bound ANXA1 and statistically significant increase by coumestrol. These results designate the induction of synthesis and stimulation of secretion of ANXA1 in PBMCs.

\section{Effect on Annexin-1 level and secretion in inflammatory PBMCs}

The levels of ANXA1 were also measured in inflammatory conditions. For this purpose, PBMCs taken from the same blood donors were subjected to inflammatory condition. Intracellular, extracellular and membrane bound ANXA1 level was measured as described above. Figure $2 a$ illustrates an increase in the extracellular level of ANXA1 in stimulated PBMCs, relative to control. An increase in intracellular and plasma membrane-bound ANXA1 was also observed.

In inflammatory PBMC, a net increase was seen in the total content (extracellular, intracellular and membrane bound) of ANXA1. The level of ANXA1 increased to $15 \pm 0.7$ and $11.5 \pm 0.9$ $\mathrm{ng} / \mathrm{mL}$ for coumestrol and curcumin, respectively. Likewise, an increasing trend was seen for ginestein $(8.9 \pm 0.3 \mathrm{ng} / \mathrm{mL})$ and diadzine $(9.8 \pm$ $0.3 \mathrm{ng} / \mathrm{mL})$, correspondingly. For all the compounds, an increasing trend in the levels of ANXA1 was seen in both normal and inflammatory cells. Similar to non- inflammatory
Collectively, a manifold increase in total level of ANXA1 was observed after combining the extracellular, intracellular and membrane bound contents of ANXA1 (Figure 1b). As compared to the untreated cells $(8.1 \pm 0.4 \mathrm{ng} / \mathrm{mL})$, the total content of ANXA1 was substantially increased (21.5 $\pm 0.8 \mathrm{ng} / \mathrm{mL})$ with coumestrol. With curcumin, genistein and daidzein, the level of ANXA1 increased to $14.7 \pm 1.1,13.2 \pm 0.4$ and $12.8 \pm 0.3 \mathrm{ng} / \mathrm{mL}$ respectively. Amongst all, coumestrol exhibited the strongest stimulation of ANXA1. On the other hand, curcumin also showed worth mentioning results. Ginestein and diadzine also moderately up regulated ANXA1.

condition, the potency of coumestrol was also highest in inflammatory condition.

\section{Inhibition of $S P L A_{2}-V$}

Secretory PLA $\mathrm{A}_{2}$ inhibitory activity was determined using the Ellman method. The activity was assessed by detecting free thiols using Ellman's reagent DTNB (5, 5'-Dithio-2 nitrobenzoic acid). The inhibition of $\mathrm{SPLA}_{2}$ activity from human source was determined by different concentrations of the inhibitors. The $\mathrm{IC}_{50}$ values for $\mathrm{SPLA}_{2}$ were calculated by linear $\mathrm{XY}$ scattered plot (Table 1). The inhibition of $\mathrm{SPLA}_{2}$ activity varied for different inhibitors at different concentrations. ANXA1 inhibited $\mathrm{SPLA}_{2}$ in a dose-dependent manner. As the concentration of ANXA1 was increased, a corresponding decrease in the enzyme activity was observed.ANXA1 preferentially inhibited $\mathrm{SPLA}_{2}$ enzyme activity with an $\mathrm{IC}_{50}$ value of $4.9 \times 10^{-7}$ and showed $>80 \%$ at $400 \mathrm{ng} / \mathrm{mL}$. Dexamethasone also exhibited $\mathrm{SPLA}_{2}$ inhibition in a dose dependent manner with an $\mathrm{IC}_{50}$ value of $0.61 \pm 0.1 \mu \mathrm{M}$ (Figure 3 and Table 1). Similarly, curcumin, genistein and daidzein 
inhibited the $\mathrm{SPLA}_{2}$ activity in a concentration dependent manner (Figure 4 and Table 1). Of all the compounds, curcumin exhibited the strongest inhibition on $\mathrm{SPLA} \mathrm{A}_{2}$ enzyme activity with an $\mathrm{IC}_{50}$ value of $11.1 \pm 0.3 \mu \mathrm{M}$. Among the

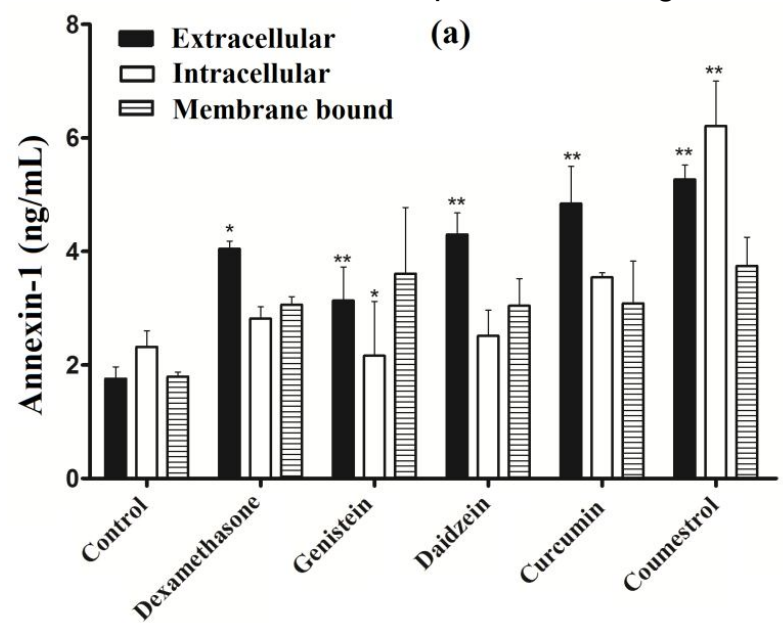

phytoestrogens, genistein showed the strongest activity with an $\mathrm{IC}_{50}$ value of $13.6 \pm 0.6 \mu \mathrm{M}$. Coumestrol also moderately inhibited $\mathrm{SPLA}_{2}$ activity in a concentration dependent manner

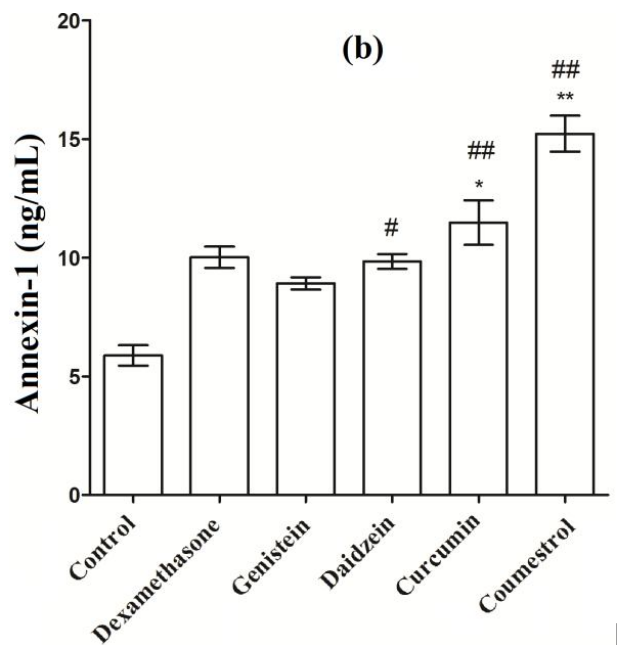

Figure 2:

(a) Concentration of extracellular, intracellular and plasma membrane bound levels of ANXA1 in inflammatory PBMC in the absence of compounds (control), Dexamethasone $(0.4 \mu \mathrm{g} / \mathrm{mL}$ ) and in the presence of compounds $(10 \mu \mathrm{g} / \mathrm{mL})$. (b) Total content of ANXA1 level in inflammatory PBMCs.

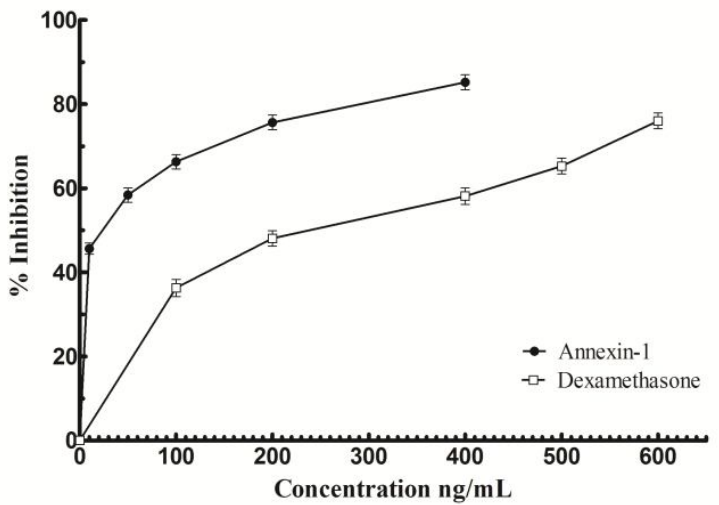

Figure 3: Concentration-dependent inhibition of SPLA2 enzyme by annexin-1(circle) and dexamethasone (square). Inhibition is expressed as percent of control. The data represents mean \pm SD $(n$ $=3$ ).

Table 1: IC50 $(\mu \mathrm{M})$ values of phytoestrogens, curcumin and annexin 1 against sPLA2 -V activity

\begin{tabular}{ll}
\hline Substance & $\mathbf{I C}_{50}(\boldsymbol{\mu M})$ \\
& \\
\hline Curcumin & $11.1 \pm 0.3$ \\
Coumestrol & $84.2 \pm 1.1$ \\
Genistein & $13.6 \pm 0.6$ \\
Daidzein & $18.0 \pm 0.6$ \\
Annexin-1 & $4.9 \times 10^{-1} \pm 0.3 \times 10^{-1}$ \\
Dexamethasone & $0.6 \pm 0.01$ \\
\hline
\end{tabular}

\section{DISCUSSION}

ANXA1 role as an anti-inflammatory protein has been brought to limelight in recent years. ANXA1 was initially thought to be just a cytosolic protein

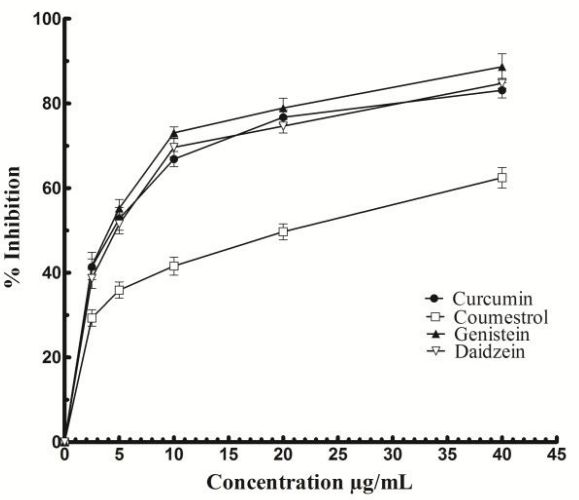

Figure 4: Concentration-dependent inhibition of sPLA2-V enzyme by curcumin, coumestrol, genistein and daidzein. Inhibition is expressed as percent of control. The data represents mean $\pm \operatorname{SD}(n=3)$.

to exert its anti-inflammatory effects through inhibition of $\mathrm{PLA}_{2}$. However, recent studies on ANXA1 have uncovered new effects and actions of ANXA1. In resting conditions, human neutrophils, monocytes and macrophages constitutively contain ANXA1 [13]. ANXA1 expression and function with GCs treatment are already known but the intracellular signalling pathways involved in the expression of ANXA1 in response to steroidal hormones are still unclear. Although some reports have illustrated that GCs up-regulate ANXA1 synthesis by genomic mechanisms [14], different intracellular studies state that this effect is independent of the activation of nuclear GCs receptors. In agreement with these reports, a recent study reported that in CCRFCEM cells, ANXA1 
synthesis was independent of the nuclear GCs receptors [15]. Dexamethasone significantly increases the cellular content of ANXA1 when incubated overnight. The overnight incubation of PBMCs with $10 \mu \mathrm{g} / \mathrm{mL}$ of investigated compounds result in the up-regulation of ANXA1. Moreover, a significant increase in the amount of ANXA1 excreted out of plasma membrane was also observed. It has been reported that the increase in the cellular turnover ofANXA1 may cause a rapid export of the proteins from intracellular stores to extracellular sites and as a consequence the de novo synthesis of proteins may took place to replenish the depleted intracellular levels [16]. Based on these findings, our results indicate that the investigated compounds may have a potential to efficiently stimulate the ANXA1 secretion.

Recent studies on the induction of ANXA1 expression have shown that chemically similar estrogen hormones also have role in the induction of the ANXA1. In studies carried out previously, researchers had demonstrated that in human lymphoblastic CCRF-CEM cell line, estrogen hormone and $17 \quad \beta$-estradiol $\left(E_{2} \beta\right)$ induced the synthesis of ANXA1 [15]. It is well established that $E_{2} \beta$ exerts major effects on cell growth, differentiation and function by specifically interacting with intracellular estrogen receptors (ER) [17]. The complex $E_{2} \beta$-ER migrates to the nucleus of the cells, where it binds to estrogenresponsive elements present in the genomic DNA. It was reported that the up-regulation of ANXA1 was due to the action of $E_{2} \beta$ on estrogen receptors.

Coumestrol, genistein and diadzine are phytoestrogens. Phytoestrogens promote estrogenic actions in mammals. Mechanistically, phytoestrogens have been shown to bind to two types of estrogen receptors: estrogen receptor $\alpha$ and receptor $\beta$, respectively. On the basis of above mentioned facts, it is hence proved that the investigated compounds resemble $E_{2} \beta$ in structure and functions, and also exhibit results similar to $E_{2} \beta$. Curcumin is renowned for its anti inflammatory effects and treatment of various diseases. In this study, it has been observed that curcumin up-regulate ANXA1 in PBMC, but the mechanisms by which curcumin up regulate ANXA1 are still unknown.

Among the PLA $\mathrm{A}_{2}$ enzymes, sPLA ${ }_{2}$ enzymes play an important role in the pathogenesis of inflammatory diseases [18]. Elevated levels of $\mathrm{SPLA}_{2}$ enzymes are detected in many inflammatory conditions. Inhibiting $\mathrm{SPLA}_{2} \mathrm{~s}$ would probably be a preferable strategy since their induced levels are predominantly associated with pathological conditions. Though, a selective inhibition of just one isoform of SPLA $\mathrm{A}_{2}$ may not be sufficient to exert the desired effect. The originally recognized activity of ANXA1 as an inhibitor of phospholipase $A_{2}\left(P L A_{2}\right)$ was at first proposed to be accountable for its anti inflammatory actions [19]. The inhibition of $\mathrm{PLA}_{2}$ activity, including the production of arachadonic acid, was thought to be a result of ANXA1 binding to the substrate, rather than directly to the enzyme, leading to the depletion of substrate sites and a subsequent reduction of $\mathrm{PLA}_{2}$ activity. However, this idea was reassessed and it is now obvious that a secretory form $\left(\mathrm{sPLA}_{2}\right)$ as well as a cytosolic form of PLA ${ }_{2}\left(\mathrm{CPLA}_{2}\right)$ exist. ANXA1 has shown the inhibition of $\mathrm{SPLA}_{2}$ in concentration dependent manner. The same mechanism has also been observed for $\mathrm{CPLA}_{2}$ inhibition [20].

Anti inflammatory properties of GCs have been attributed to the liberation and enhanced synthesis of ANXA1, which inhibit PLA ${ }_{2}$, resulting in a decreased eicosanoid synthesis. However in the current study, dexamethasone has been found to have inhibited the $\mathrm{SPLA}_{2}$ in a concentration dependent manner. In the previous studies, dexamethasone had been reported to inhibit the PLA ${ }_{2}$ in U937 cells but, the expression of ANXA1 was not inducible by GCs in these cells [21].

Flavonoids are antioxidants known to act as antiinflammatory compounds by scavenging the free radicals. Therefore, a single molecule having both potencies of $\mathrm{PLA}_{2}$ inhibition as well as antioxidant activity can serve as a better antiinflammatory molecule. In the present study, the flavonoids, genistein and diadzine inhibited $\mathrm{sPLA}_{2}-\mathrm{V}$ in a concentration dependent manner. Many inhibitors inhibit the $\mathrm{PPLA}_{2}$ activity either by binding to the substrate, or by chelating with calcium. But the inhibition of other $\mathrm{SPLA}_{2}$ isomers by genistein was observed to be independent of substrate and chelation of calcium, though sPLA $\mathrm{S}_{2}$ isomers exhibited more than $70 \%$ homology [22]. Diadzine and genistein belong to same class and have structural and functional similarities. So, it is possible that diadzine has same mechanism as followed by the genistein.

\section{CONCLUSION}

The results illustrate that the phytoestrogen and curcumin have potentials to induce synthesis and secretion of ANXA1 in peripheral blood mononuclear cells (PBMCs). Our findings on $\mathrm{SPLA}_{2}-\mathrm{V}$ inhibition provide further evidence to rationalize the anti-inflammatory activities of the tested compounds. The present findings on 
$\mathrm{sPLA}_{2}-\mathrm{V}$ inhibitory functionality should encourage further investigations that would address other $\mathrm{PLA}_{2}$ isoforms in inflammatory cascades.

\section{ACKNOWLEDGEMENT}

The present study was supported by a grant from Universiti Kebangsaan Malaysia (no. GUP-UKM2011-010).

\section{REFERENCES}

1. Nathan C. Points of control in inflammation. Nature 2002; 420: 846-852.

2. Lim L, Pervaiz S. Annexin 1: the new face of an old molecule. FASEB J 2007; 21: 968-971.

3. D'Acquisto F, Merghani A, Lecona E, Rosignoli G, Raza $K$, Buckley CD, Flower RJ, Perretti M. Annexin-1 modulates $T$-cell activation and differentiation. Blood 2007; 9: 1095-1102.

4. Dennis EA. Diversity of group types, regulation, and function of phospholipase $A_{2}$. J Biol Chem 1994; 269: 13057-13060.

5. Yedgar S, Lichtenberg D, Schnitzer E. Inhibition of phospholipase $A_{2}$ as a therapeutic target. Biochim Biophys Acta, Mol Cell Biol Lipids 2000; 1488 . 182-187.

6. Schacke $H$, Docke WD, Asadullah K. Mechanisms involved in the side effects of glucocorticoids. Pharmacol \& Ther 2002; 96: 23-43.

7. Morin D, Barthelemy S, Zini R, Labidalle S, Tillement JP. Curcumin induces the mitochondria permeability transition poremediated by membrane protein thiol oxidation. FEBS Lett 2001; 495: 131 136.

8. Amin A, Buratovich $M$. The anti-cancer charm of flavonoids: A cup-of-tea will do. Recent Pat AntiCancer Drug Discovery 2007; 2: 109-117.

9. Choo MK, Park EK, Yoon HK, Kim DH. Antithrombotic and antiallergic activities of daidzein, metabolite of puerarin and daidzin produced by human intestinal microflora. Biol Pharm Bull 2002; 25: 1328-1332.

10. Coméra C, Russo-Marie F. Glucocorticoid-induced annexin 1 secretion by monocytes and peritoneal leukocytes. Br J Pharmacol 1995; 115: 1043-1047.

11. Sudlow W, Carey F, Forder R, Rothwell NJ. The role of lipocortin-1 in dexamethasone-induced supperssion of PGE2 and TNF alpha release from human peripheral blood mononuclear cells. $\mathrm{Br} J$ Pharmacol 1996; 117: 1449-1456.
12. Ellman $G L$, Courtney KD, Andres VJ, Feather-Stone RM. A new and rapid colorimetric determination of acetylcholinesterase activity. Biochem Pharmacol 1961; 7: 88-95

13. Arur S, Uche UE, Rezaul K, Fong M, Scranton V, Cowan AE, Mohler W, Han DK. Annexin $I$ is anendogenous ligand that mediates apoptotic cell engulfment. Dev Cell 2000; 4: 587-598.

14. Perretti M, Christian H, Wheller SK, Aiello I, Mugridge KG, Morris JF, Flower RJ, Goulding NJ. Annexin I is stored within gelatinase granules of human neutrophils and mobilised on the cell surface upon adhesion but not phagocytosis. Cell Biol Int 2000; 24: 163-174.

15. Buckingham JC, Flower RJ. Lipocortin 1, a second messenger of glucocorticoid action in the hypothalamo-pituitary-adrenocortical axis. Mol Med Today 1997; 3: 296-302.

16. Castro-Caldas $M$, Duarte $C B$, Carvalho $A P$, Lopes $M C$. $17 \beta$-estradiol promotes the synthesis and the secretion of annexin 1 in the CCRF-CEM human cell line. Mediators Inflamm 2001; 10: 245-251.

17. Philip JG, Flower RJ, Buckingham JC. Blockade of the classical pathway of protein secretion does not affect the cellular exportation of lipocortin-1. Regul Pept 1998; 73: 133-139.

18. Benten WPM, Lieberherr M, Giese G, Wunderlich F. Estradiol binding to cell surface raises free calcium in T cells. FEBS Lett 1998; 422: 349-353.

19. Kudo I, Murakami M. Phospholipase $A_{2}$ enzymes. Prostaglandins Other Lipid Mediat 2002; 68-69: 358.

20. Croxtall JD, Choudhury $Q$, Tokumoto $H$, Flower $R J$. Lipocortin-1 and the control of arachidonic acid release in cell signalling. Glucocorticoids (changed from glucorticoids) inhibit $G$ protein-dependent activation of cPLA2 activity. Biochem Pharmacol 1995; 50: 465-474.

21. Koehler L, Hass R, Goppelt-Struebe M, Kaever V, Resch K. Differential effect of dexamethasone on the regulation of phospholipase A2 and prostanoid synthesis in undifferentiated and phorbolesterdifferentiated U937 cells. J Cell Biochem 1989; 40b: 397-406.

22. Kim HP, Son $\mathrm{KH}$, Chang HW, Kang SS. Antiinflammatory plant flavonoids and cellular action mechanism. J Pharmacol Sci 2004; 96: 229-245.

23. World Medical Association. Ethics Unit. Declaration of Helsinki 2007. www.wma.net/e/ethicsunit/helsinki. htm 